\title{
Cost-Effectiveness Evaluation of Etoricoxib versus Celecoxib and Nonselective NSAIDs in the Treatment of Ankylosing Spondylitis in Norway
}

\author{
Jeroen P. Jansen ${ }^{1}$ and Stephanie D. Taylor ${ }^{2}$ \\ ${ }^{1}$ Mapi Values, Boston, MA 02114, USA \\ ${ }^{2}$ Global Health Outcomes, Outcome Research, Merck \& Co., Inc., One Merck Drive, P. O. Box 100, WS2E-85, \\ Whitehouse Station, NJ 08889, USA
}

Correspondence should be addressed to Stephanie D. Taylor, stephanie_taylor@merck.com

Received 7 January 2011; Accepted 20 March 2011

Academic Editor: Ruben Burgos-Vargas

Copyright (C) 2011 J. P. Jansen and S. D. Taylor. This is an open access article distributed under the Creative Commons Attribution License, which permits unrestricted use, distribution, and reproduction in any medium, provided the original work is properly cited.

\begin{abstract}
Objectives.To evaluate the cost-effectiveness of etoricoxib $(90 \mathrm{mg}$ ) relative to celecoxib (200/400 $\mathrm{mg})$, and the nonselective NSAIDs naproxen $(1000 \mathrm{mg})$ and diclofenac $(150 \mathrm{mg})$ in the initial treatment of ankylosing spondylitis in Norway. Methods. A previously developed Markov state-transition model was used to estimate costs and benefits associated with initiating treatment with the different competing NSAIDs. Efficacy, gastrointestinal and cardiovascular safety, and resource use data were obtained from the literature. Data from different studies were synthesized and translated into direct costs and quality adjusted life years by means of a Bayesian comprehensive decision modeling approach. Results. Over a 30-year time horizon, etoricoxib is associated with about 0.4 more quality adjusted life years than the other interventions. At 1 year, naproxen is the most cost-saving strategy. However, etoricoxib is cost and quality adjusted life year saving relative to celecoxib, as well as diclofenac and naproxen after 5 years of followup. For a willingness-to-pay ceiling ratio of 200,000 Norwegian krones per quality adjusted life year, there is a $>95 \%$ probability that etoricoxib is the most-cost-effective treatment when a time horizon of 5 or more years is considered. Conclusions. Etoricoxib is the most cost-effective NSAID for initiating treatment of ankylosing spondylitis in Norway.
\end{abstract}

\section{Introduction}

Ankylosing spondylitis (AS) is a chronic inflammatory rheumatic disease that affects the axial skeleton, causing characteristics inflammatory back pain, which can lead to structural and functional impairments. Asymmetric peripheral arthritis is present in about $20-40 \%$ of patients with AS [1]. In Europe, estimates of prevalence of ankylosing spondylitis vary by tenfold from $0.08 \%$ to $0.86 \%$ [2-4]. The direct costs of AS are substantial. In Europe, the annual total direct costs per patient have been estimated at $€ 1,800$ to $€ 2,800$ [5]. The introduction of antitumour necrosis factor alpha (anti$\mathrm{TNF} \alpha$ ) agents has increased the direct cost of AS [6].

The first-line treatment of AS is nonsteroidal antiinflammatory drugs (NSAIDs) [7-9]. Patients with severe disease refractory to NSAIDs are eligible for anti-TNF $\alpha$ agents [10]. The nonselective NSAIDs (nsNSAIDs) have been associated with an increased risk of gastrointestinal (GI) adverse events such as ulcers and GI bleeding because of their inhibition of the gastroprotective COX-1 isoform. COX-2 selective inhibitors were developed with reduced GI toxicity when compared with nonselective NSAIDs. Etoricoxib and celecoxib have been demonstrated to have a superior upper gastrointestinal (GI) safety profile [11-14]. The MEDAL (Multinational Etoricoxib and Diclofenac Arthritis Long Term) program demonstrated the risk of cardiovascular (CV) events with etoricoxib $(60 \mathrm{mg} / \mathrm{d}$ and $90 \mathrm{mg} / \mathrm{d})$ comparable to diclofenac ( $75 \mathrm{mg}$ bid and $50 \mathrm{mg}$ tid) [15]. On the efficacy side, etoricoxib has been shown, at doses of $90 \mathrm{mg}$ and $120 \mathrm{mg}$, to be superior compared to naproxen $1000 \mathrm{mg}$ in the treatment of AS [16]. Celecoxib (200 mg and $400 \mathrm{mg}$ ) showed comparable efficacy to diclofenac $(150 \mathrm{mg})$ [17]. 
Given the economic burden of AS, a cost-effectiveness analysis of interventions for AS is warranted. The objective of this study was to evaluate the cost-effectiveness of etoricoxib (90 mg) compared to celecoxib (200 and $400 \mathrm{mg}$ ), diclofenac $(150 \mathrm{mg})$, and naproxen $(1000 \mathrm{mg})$ in the treatment of patients with AS in Norway. Analyses were performed from the health care perspective.

\section{Methods}

In the present economic evaluation, a comprehensive decision Bayesian modelling approach was used which integrates evidence synthesis and parameter estimation for efficacy and safety with cost-effectiveness modeling in a single unified framework [18].

2.1. Markov Model Description. A previously published Markov-state transition model was used to estimate the costeffectiveness of etoricoxib versus celecoxib and nsNSAIDs in the treatment of AS patients requiring daily NSAID treatment [19]. The model consisted of eight health states reflecting treatment received: (1) “initial NSAID” (etoricoxib, celecoxib, or nsNSAIDs, depending on intervention arm of the model), (2) "initial NSAID with proton-pump inhibitor (PPI)," (3) alternative nsNSAIDs with PPI, (4) alternative nsNSAID with PPI and aspirin, (5) alternative nsNSAID, (6) anti-TNF $\alpha$ treatment, (7) discontinued anti$\mathrm{TNF} \alpha$ treatment, and (8) death. All patients start in health state 1 . Transitions from state to state were determined by lack of treatment efficacy, and the different types of events as presented in Table 1. Figure 1 presents the different types of cost generating GI, CV, and other events relevant to each Markov cycle.

For each health state, utilities were assigned based on the Bath Ankylosing Spondylitis Functional Index (BASFI) and the Bath Ankylosing Spondylitis Disease Activity Index (BASDAI) [20]. Over time, BASFI will worsen thereby decreasing utilities. Disutilities were assigned based on occurrence of adverse events. Drug acquisition costs, and cost due to adverse events were taken into account.

The model was developed with a cycle length of 1 year. The model followed individuals for a maximum of 30 cycles (30 years) as by this time the majority of individuals had reached the absorbing state (i.e., death).

\subsection{Source Data}

2.2.1. Efficacy: BASFI, BASDAI, and Discontinuation due to Lack of Efficacy. The efficacy of etoricoxib, celecoxib, diclofenac, or naproxen in AS regarding BASFI, BASDAI, and discontinuation was obtained from a previously performed systematic review and Bayesian mixed treatment comparison (MTC) of randomized controlled trials using noninformative prior distributions $[19,21,22]$. In Table 2 the individual study results are presented. In Table 3, the results of the MTC as used in the cost-effectiveness analysis are presented.

For the model analysis, the expected change from baseline $(\mathrm{CFB})$ estimates for BASFI and BASDAI by treatment were subtracted from background BASFI and BASDAI values which develop over time. Over time, an increase in BASFI of 0.5 (scale 0-100) per annum was assumed $[6,20]$. It was assumed that background BASDAI scores remained stable over time $[16,23,24]$. For patients who continue responding to treatment, it is assumed that their treatment effect regarding BASFI and BASDAI (i.e., the CFB scores) remain constant over time. Patients who switched to another nsNSAIDs were assumed to have the average treatment effect of diclofenac and naproxen as obtained from the MTC. For patients that switched to anti-TNF $\alpha$, a treatment effect of 23 points and 19 points was used for BASFI and BASDAI, respectively.

It was assumed that $10 \%$ withdraw from anti-TNF $\alpha$ each year $[20,25]$. For patients who withdraw from anti-TNF $\alpha$ treatment BASDAI, and BASFI measurements revert back to baseline values as reported by Ara et al. [20].

2.2.2. Safety. An overview of all event-related parameters is presented in Table 3. Incidence rates of an upper GI perforation, ulcer, or bleeding (PUB) for etoricoxib, celecoxib, and the nsNSAIDs were estimated with an indirect comparison of the relative incidence rates versus placebo as reported by Ramey et al. (OA, RA, and AS patients) and Silverstein et al. (OA and RA patients) $[11,14,19]$. Incidence rates for suspected PUBs were calculated by subtracting the PUBS from all-investigator-reported PUBs by Ramey et al. [11]. Rates of minor GI symptoms were based on discontinuations due to clinical GI events in the MEDAL programme [28]. Except for PUBs, the rates for other upper GI events with etoricoxib were also used for the celecoxib arm of the model. The probabilities of treatment of GI events were based on Moore et al. [29].

The incidence of a thrombotic CV event with etoricoxib, diclofenac, and naproxen were obtained by performing an indirect comparison of the results from the MEDAL programme by Cannon et al. and the relative incidence rate of etoricoxib versus naproxen from a meta-analysis of thrombotic CV events in 12 phase II-IV clinical trials [15, $19,30]$. Rates for etoricoxib were also used for the celecoxib arm of the model. The occurrence of edema, hypertension, coronary heart failure, hepatic adverse events, and renal events were obtained from the MEDAL programme as well [15]. For anti-TNF $\alpha$ treatment, and treatment after anti$\mathrm{TNF} \alpha$, no adverse events were taken into consideration.

The adverse event rate for second-line nsNSAID therapy was assumed to be equal to the average of those obtained for diclofenac and naproxen, with the exception of the incidence of an upper GI event in a patient receiving nsNSAID plus PPI therapy, which was assumed to be reduced by $40 \%$ [29]. The GI and CV risk for a patient who switched to nsNSAID plus aspirin and PPI was assumed to be comparable to that for nsNSAID alone.

2.2.3. Mortality. The case-fatality of a UGI PUB or LGI Bleed was $3.6 \%[29,31]$. A $13 \%$ case-fatality for a CV event was used for etoricoxib and celecoxib, and $12.8 \%$ casefatality for nsNSAIDs [15]. For patients not experiencing GI 
TABLE 1: Transitions between different health states of Markov model due to events and lack of efficacy.

\begin{tabular}{|c|c|c|c|c|c|c|c|}
\hline \multirow[b]{2}{*}{ From } & \multicolumn{7}{|c|}{ To } \\
\hline & Initial NSAID & $\begin{array}{l}\text { Initial NSAID } \\
\text { with PPI }\end{array}$ & $\begin{array}{l}\text { Alternative } \\
\text { nsNSAID }\end{array}$ & $\begin{array}{l}\text { Alternative } \\
\text { nsNSAID with } \\
\text { PPI }\end{array}$ & $\begin{array}{l}\text { Alternative } \\
\text { nsNSAID with } \\
\text { PPI \& aspirin } \\
\end{array}$ & Anti-TNF $\alpha$ & $\begin{array}{l}\text { Discontinued } \\
\text { Anti-TNF } \alpha\end{array}$ \\
\hline Initial NSAID & $\begin{array}{l}\text { (i) No events } \\
\text { (ii) Events w/o } \\
\text { switch }\end{array}$ & $\begin{array}{l}\text { (i) Suspected } \\
\text { PUB } \\
\text { (ii) Minor upper } \\
\text { GI symptoms }\end{array}$ & $\begin{array}{l}\text { (i) Edema, } \\
\text { hypertension, } \\
\text { hepatic, CHF, } \\
\text { renal; all with } \\
\text { switching } \\
\text { treatment } \\
\text { (ii) Lack of } \\
\text { efficacy }\end{array}$ & Upper GI PUB & CV event & NA & NA \\
\hline $\begin{array}{l}\text { Initial NSAID } \\
\text { with PPI }\end{array}$ & NA & $\begin{array}{l}\text { (i) Suspected } \\
\text { PUB } \\
\text { (ii) Minor upper } \\
\text { GI symptoms } \\
\text { (iii) No events } \\
\text { (iv) Events w/o } \\
\text { switch }\end{array}$ & NA & $\begin{array}{l}\text { (i) Upper GI } \\
\text { (ii) PUB Edema, } \\
\text { hypertension, } \\
\text { hepatic, CHF, } \\
\text { renal; all with } \\
\text { switching tx } \\
\text { (iii) Lack of } \\
\text { efficacy }\end{array}$ & CV event & NA & NA \\
\hline $\begin{array}{l}\text { Alternative } \\
\text { nsNSAID }\end{array}$ & NA & NA & $\begin{array}{l}\text { (i) No events } \\
\text { (ii) Events w/o } \\
\text { switch }\end{array}$ & $\begin{array}{l}\text { (i) Suspected } \\
\text { PUB } \\
\text { (ii) Minor upper } \\
\text { GI symptoms }\end{array}$ & CV event & $\begin{array}{l}\text { (i) Upper GI } \\
\text { PUB } \\
\text { (ii) Edema, } \\
\text { hypertension, } \\
\text { hepatic, CHF, } \\
\text { renal; all with } \\
\text { switching } \\
\text { treatment } \\
\text { (iii) Lack of } \\
\text { efficacy }\end{array}$ & NA \\
\hline $\begin{array}{l}\text { Alternative } \\
\text { nsNSAID with } \\
\text { PPI }\end{array}$ & NA & NA & NA & $\begin{array}{l}\text { (i) Suspected } \\
\text { PUB } \\
\text { (ii) Minor upper } \\
\text { GI symptoms } \\
\text { (iii) No events } \\
\text { (iv) Events w/o } \\
\text { switch }\end{array}$ & CV event & $\begin{array}{l}\text { (i) Upper GI } \\
\text { PUB } \\
\text { (ii) Edema, } \\
\text { hypertension, } \\
\text { hepatic, CHF, } \\
\text { renal; all with } \\
\text { switching } \\
\text { treatment } \\
\text { (iii) Lack of } \\
\text { efficacy }\end{array}$ & NA \\
\hline $\begin{array}{l}\text { Alternative } \\
\text { nsNSAID with } \\
\text { PPI \& aspirin }\end{array}$ & NA & NA & NA & NA & $\begin{array}{l}\text { Suspected PUB } \\
\text { (i) Minor upper } \\
\text { GI symptoms } \\
\text { (ii) No events } \\
\text { (iii) Events w/o } \\
\text { switch }\end{array}$ & $\begin{array}{l}\text { (i) Upper GI } \\
\text { PUB } \\
\text { (ii) CV event } \\
\text { (iii) Edema, } \\
\text { hypertension, } \\
\text { hepatic, CHF, } \\
\text { renal; all with } \\
\text { switching } \\
\text { treatment } \\
\text { (iv) Lack of } \\
\text { efficacy }\end{array}$ & NA \\
\hline Anti-TNF $\alpha$ & NA & NA & NA & NA & NA & Other & $\begin{array}{l}\text { Lack of } \\
\text { efficacy }\end{array}$ \\
\hline $\begin{array}{l}\text { Discontinued } \\
\text { anti-TNF } \alpha\end{array}$ & NA & NA & NA & NA & NA & NA & All \\
\hline
\end{tabular}


TABLE 2: Individual studies and results included for mixed treatment comparison of BASFI, BASDAI and discontinuation due to lack of efficacy.

\begin{tabular}{|c|c|c|c|c|c|c|c|c|c|c|c|c|}
\hline & \multirow{2}{*}{\multicolumn{2}{|c|}{ Placebo }} & \multicolumn{4}{|c|}{ Celecoxib } & \multirow{2}{*}{\multicolumn{2}{|c|}{$\begin{array}{c}\text { Naproxen* } \\
1000 \text { mg }\end{array}$}} & \multirow{2}{*}{\multicolumn{2}{|c|}{$\begin{array}{l}\text { Etoricoxib } \\
90 \mathrm{mg}\end{array}$}} & \multirow{2}{*}{\multicolumn{2}{|c|}{$\begin{array}{c}\text { Diclofenac* } \\
150 \mathrm{mg}\end{array}$}} \\
\hline & & & \multicolumn{2}{|c|}{$200 \mathrm{mg}$} & \multicolumn{2}{|c|}{$400 \mathrm{mg}$} & & & & & & \\
\hline & Mean & $(\mathrm{SE})$ & Mean & $(\mathrm{SE})$ & Mean & (SE) & Mean & $(\mathrm{SE})$ & Mean & $(\mathrm{SE})$ & Mean & $(\mathrm{SE})$ \\
\hline \multicolumn{13}{|c|}{ BASFI } \\
\hline Barkhuizen et al. [26] & 2.00 & $(3.00)$ & -9.00 & $(0.50)$ & -11.00 & $(1.00)$ & -16.00 & $(2.00)$ & & & & \\
\hline Van der Heijde et al. [16] & -4.00 & $(1.90)$ & & & & & -14.60 & $(1.80)$ & -19.40 & $(1.80)$ & & \\
\hline Dougados et al. [27] & 1.30 & $(2.03)$ & -11.90 & $(2.46)$ & & & & & & & & \\
\hline Sieper et al. [17] & & & -8.00 & $(1.62)$ & -9.00 & $(1.23)$ & & & & & -9.00 & $(1.45)$ \\
\hline \multicolumn{13}{|c|}{ BASDAI } \\
\hline Van der Heijde et al. [16] & -6.40 & $(1.90)$ & & & & & -23.6 & $(1.80)$ & -28.60 & $(1.80)$ & & \\
\hline Sieper et al. [17] & & & -9.90 & $(1.71)$ & -13.20 & $(1.40)$ & & & & & -14.80 & $(1.41)$ \\
\hline \multicolumn{13}{|c|}{ Discontinuation for lack of efficacy and (sample size) } \\
\hline & $r$ & $n$ & $r$ & $n$ & $r$ & $n$ & $r$ & $n$ & $r$ & $n$ & $r$ & $n$ \\
\hline Barkhuizen et al. [26] & 59 & 156 & 25 & 137 & 23 & 161 & 17 & 157 & & & & \\
\hline Van der Heijde et al. [16] & 44 & 93 & & & & & 20 & 97 & 8 & 100 & & \\
\hline Dougados et al. [27] & 31 & 76 & 18 & 80 & & & & & & & & \\
\hline
\end{tabular}

${ }^{*}$ For mixed treatment comparison of BASDAI, the results of naproxen and diclofenac were considered as the group nsNSAID.

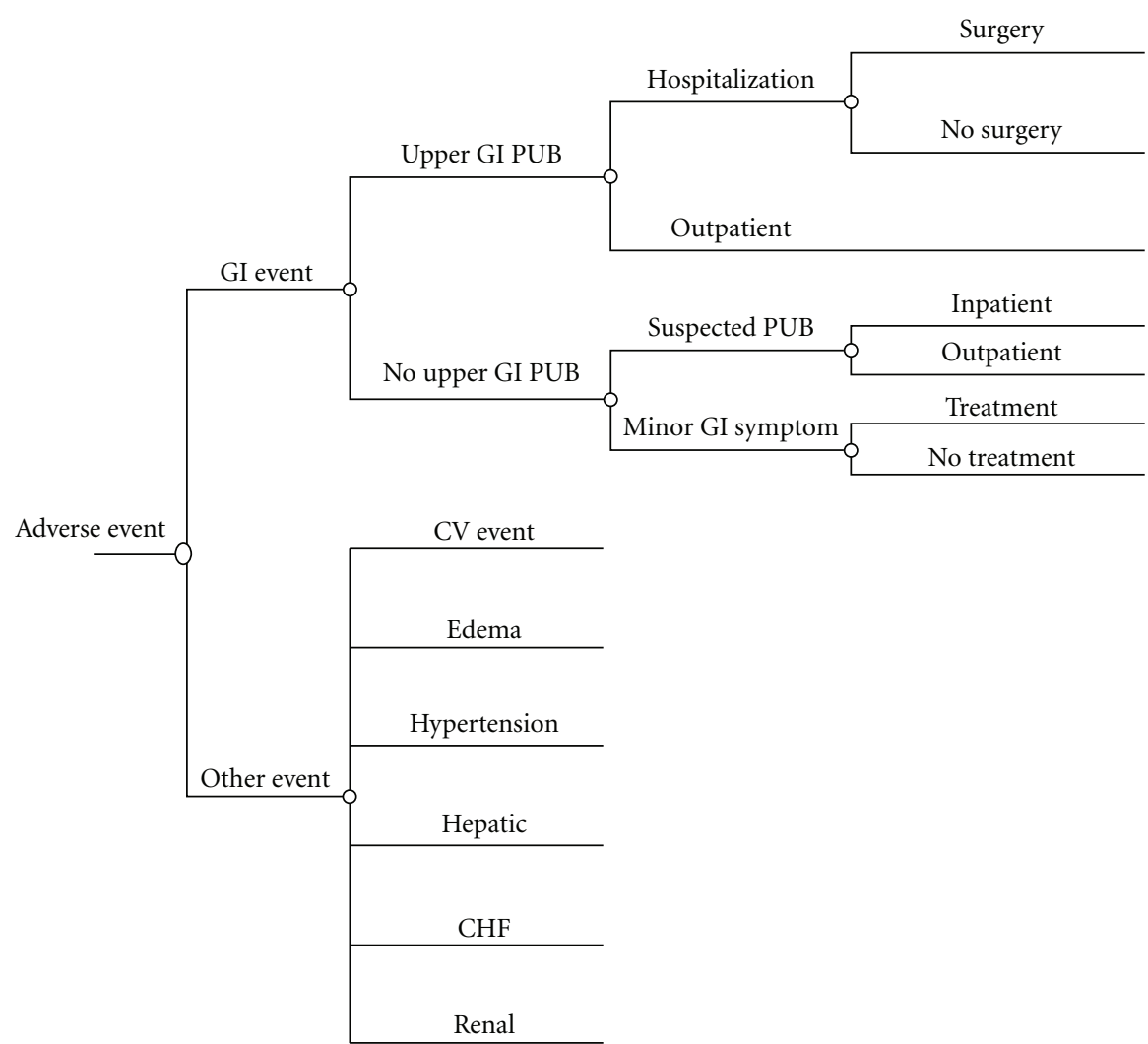

FIGURE 1: Tree structure reflecting events resulting in costs and potential changes in treatment (i.e., transitions between health states of the Markov model).

or CV adverse events, a Norwegian annual age-dependent mortality was used, as obtained from the life tables for Norway [32]. For the evaluation, an AS population with an average age of 45 was assumed (base-case scenario) [16].
2.2.4. Utilities. Utilities reflect the preference for a certain health state and are measured on $0-1$ scale. A value of 1 reflects perfect health and 0 represents death. By summarizing the utility value over time, quality adjusted life years (QALYs) are created. Life years were transformed into QALYs 
using a relation between utility (EQ-5d) and BASFI and BASDAI as derived by Ara et al. [20]: Utility $=0.923-$ $0.004^{*}$ BASFI $-0.004^{*}$ BASDAI. Utility loss associated with adverse events was obtained from the literature [29, 33-36].

2.2.5. Costs. Annual drug acquisition costs were calculated based on the most commonly prescribed drug within a drug class and obtained from the Norwegian Medicines Agency (NoMA September 2007). For anti-TNF treatment, annual costs of etanercept were used. For each type of GI event, numbers of units of health care resource use were assigned and respective unit costs applied to all healthcare resources to calculate the cost per event. The key cost items for GI events included costs of treatment (drugs and dispensing), GP consultations, investigations, inpatient days, and surgery. Costs of thrombotic CV events were weighted according to rates in the MEDAL study. All costs of adverse events were limited to the first year. Cost for the other adverse events (i.e., edema, hypertension, hepatic, and renal) were not taken into consideration. Drug costs related to adverse events were obtained from NoMA (September 2007); costs related to GP visits were obtained from the Norwegian Medical Association (July 2007), and inpatient costs related to events were obtained from the DRG price list [37]. All costs were expressed in 2007 Norwegian kroner (NOK).

2.3. Estimating Model Outcomes. Given the Markov statetransition model structure, the source data were combined and translated into the following outcomes: quality adjusted life years, drug acquisition costs, costs of adverse events, total costs, and net monetary benefit (NMB) calculated as QALYs multiplied with a willingness-to pay ratio (WTP) minus costs. WTP is the amount that decision makers are willingto pay per additional QALY gained. Effects and costs were all discounted at $4 \%$ in the base-case scenario.

Since the model was fully probabilistic, outcomes were estimated with MCMC simulation using WinBUGS v 1.4. For each iteration of the model, new parameter values were sampled from the estimated (posterior) or defined distributions for efficacy, safety, and costs (see Table 3). The model was evaluated by averaging output values over many iterations (i.e., 10.000), allowing uncertainty in model parameters to be accounted for. For each iteration, the QALYs and cost accrued for each cycle were calculated for each of the treatments according to Sonnenberg and Beck [38]. At the end of each iteration, the cumulative QALYs and costs over the cycles were obtained by summing the results over all cycles. Next, the incremental cost, incremental QALYs, and incremental cost-effectiveness ratio (ICER = incremental costs/incremental QALYs) of etoricoxib versus the other interventions were evaluated. The probability of cost-effectiveness was expressed with cost-effectiveness acceptability curves, calculated as the number of iterations out of the total number of iterations for which the NMB was greatest for a given treatment out of all 4 treatments. Furthermore, analysis were performed to identify the impact of uncertainty in the source data on the uncertainty in the QALYs, costs, and NMB estimates.
In the base-case scenario, etoricoxib (90 mg) was compared with celecoxib (200 mg \& $400 \mathrm{mg}$ ), diclofenac $(150 \mathrm{mg})$, and naproxen $(1000 \mathrm{mg})$. In alternative analyses, the following scenarios were evaluated: (1) celecoxib $200 \mathrm{mg}$ was used instead of celecoxib $200 \mathrm{mg} / 400 \mathrm{mg}$, (2) only GI events, (3) only CV events, (4) no adverse events, (5) no discounting on costs and effects, (6) 8\% discounting on costs and effects, (7) stable BASFI over time, and (8) assuming an age of 20 years, and (9) anti-TNF $\alpha$ costs excluded. For each scenario uncertainty in input parameters was taken into consideration, as outlined above.

\section{Results}

3.1. Base-Case Scenario. In Table 4, the results of the basecase scenario are presented for 1 year, 5 years, and 30 years of follow-up. There was more than $98 \%$ probability that etoricoxib resulted in higher expected QALYs than the other interventions of interest.

Drug costs are expected to be the highest with celecoxib (200 \& $400 \mathrm{mg}$ ) followed by etoricoxib (90 mg). The nsNSAIDs result in the lowest drug costs. After 5 years, however, the lowest drug costs can be expected for the patients for whom treatment was initiated with etoricoxib due to the higher probability of staying on initial therapy and not switching to the far more expensive anti-TNF $\alpha$ treatment. After 30 years, the difference favoring etoricoxib was even greater.

Relative to a patient starting with nsNSAIDs, the costs due to GI events were lower for a patient starting with etoricoxib or celecoxib as a result of a reduced risk of treatment-requiring GI events. After 30 years, the GI-related costs with etoricoxib were higher than with celecoxib because this latter group of patients switched quicker to anti-TNF $\alpha$, which is not associated with GI events. Until 5 years, costs related to thrombotic $\mathrm{CV}$ events were similar with etoricoxib, celecoxib, and diclofenac, and slightly higher than with naproxen. For the same reason as the GI-related costs, the CV-related costs with etoricoxib were higher than with celecoxib and diclofenac at 30 years of followup. Overall, naproxen resulted in the lowest cost at 1 year; however, at 5 years and beyond, etoricoxib resulted in the lowest direct costs of the four alternatives; at 5 year, there is a $>96 \%$ probability that the lowest costs are obtained with etoricoxib. This increased to $>99 \%$ at 30 years.

In Table 5, the difference in costs and QALYs of etoricoxib relative to the other interventions is presented. Given the more favourable outcomes regarding costs and QALYs with etoricoxib after 5 years of followup, etoricoxib is considered an economically dominant intervention. At 1 year, etoricoxib is economically dominant over celecoxib. The incremental cost-utility ratio (ICER) of etoricoxib relative to diclofenac and naproxen at 1 year was 59,221 NOK and 107,256 NOK, respectively. In Figure 2, the probability of cost-effectiveness for the different interventions at different willingness-to-pay (WTP) ratios are presented. For a WTP 200,000 NOK per QALY there is an $85 \%$ probability that etoricoxib is the most cost-effective intervention at 1 year. This increased to more 
TABLE 3: Parameters (and distributions) for cost-effectiveness evaluation.

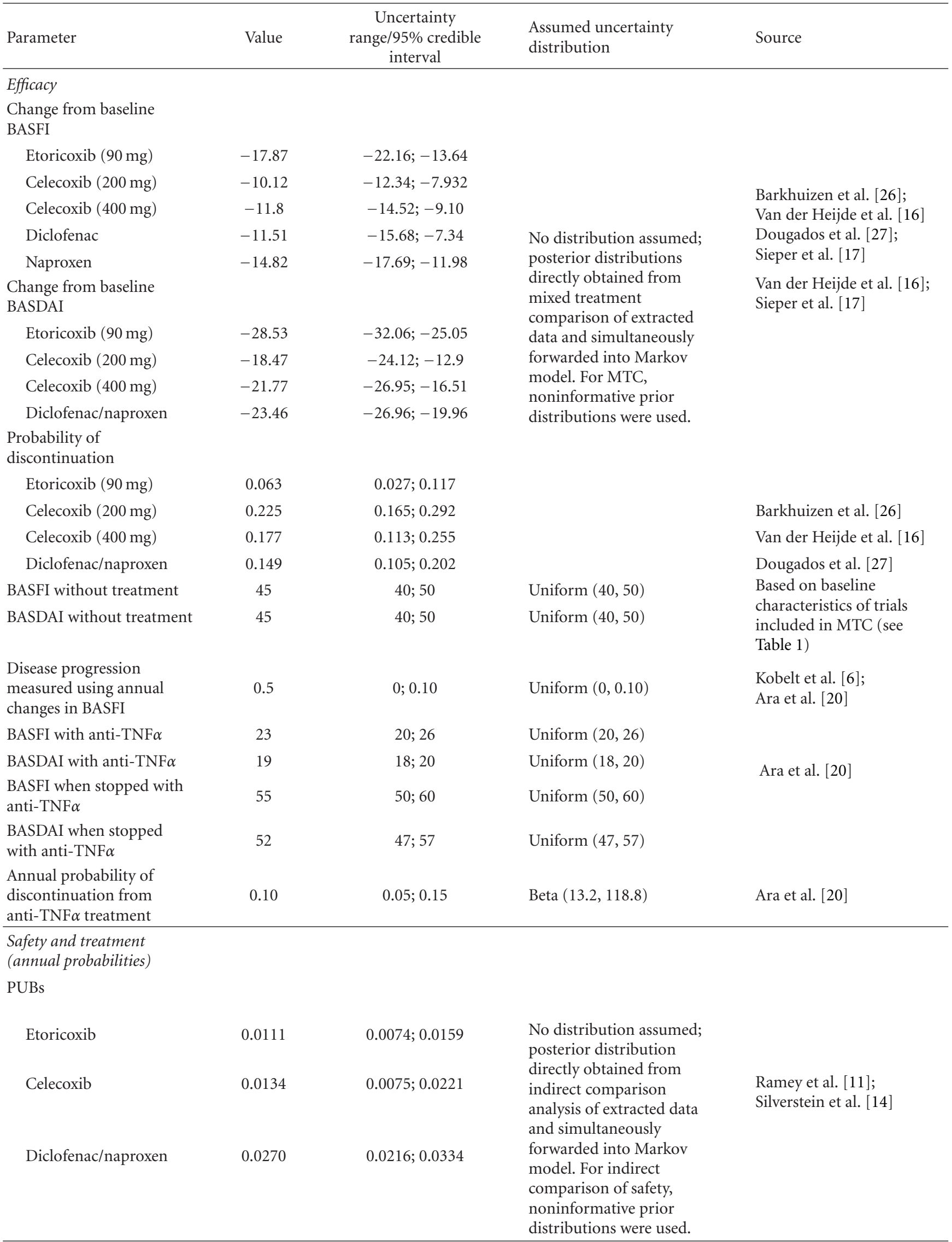


Table 3: Continued.

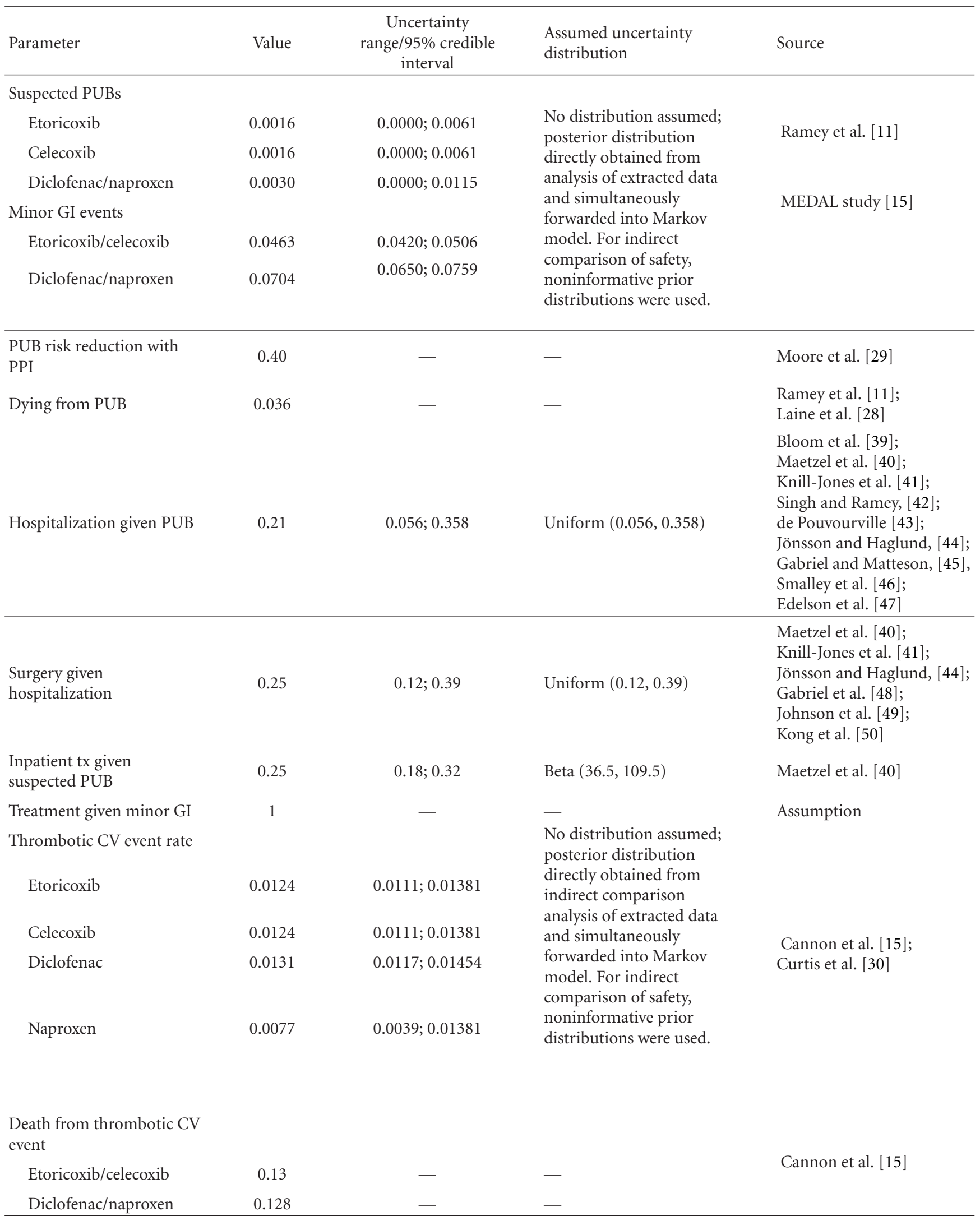


Table 3: Continued.

\begin{tabular}{|c|c|c|c|c|}
\hline Parameter & Value & $\begin{array}{c}\text { Uncertainty } \\
\text { range/95\% credible } \\
\text { interval } \\
\end{array}$ & $\begin{array}{l}\text { Assumed uncertainty } \\
\text { distribution }\end{array}$ & Source \\
\hline \multicolumn{5}{|l|}{ Edema } \\
\hline Etoricoxib/celecoxib & 0.0106 & $0.0086 ; 0.0127$ & Beta $(101.4,9459.7)$ & \\
\hline Diclofenac/naproxen & 0.0070 & $0.0054 ; 0.0088$ & Beta $(64.9,9165.4)$ & \\
\hline \multicolumn{5}{|l|}{ Hypertension } \\
\hline Etoricoxib/celecoxib & 0.0229 & $0.0200 ; 0.0260$ & Beta $(218.9,9342.0)$ & \\
\hline Diclofenac/naproxen & 0.0153 & $0.0129 ; 0.0179$ & Beta $(141.2,9088.8)$ & \\
\hline \multicolumn{5}{|l|}{ Coronary heart failure } \\
\hline Etoricoxib/celecoxib & 0.0044 & $0.0032 ; 0.0058$ & Beta $(42.1,9518.9)$ & MEDAL [15] \\
\hline Diclofenac/naproxen & 0.0026 & $0.0017 ; 0.0037$ & Beta $(24.7,9490.5)$ & \\
\hline \multicolumn{5}{|l|}{ Hepatic events } \\
\hline Etoricoxib/celecoxib & 0.0036 & $0.0025 ; 0.00489$ & Beta $(34.4,9526.6)$ & \\
\hline Diclofenac/naproxen & 0.0218 & $0.0189 ; 0.0249$ & Beta $(201.2,9028.8)$ & \\
\hline \multicolumn{5}{|l|}{ Renal events } \\
\hline Etoricoxib/Celecoxib & 0.0114 & $0.0094 ; 0.0136$ & Beta $(109.0,9452.0)$ & \\
\hline Diclofenac/Naproxen & 0.0100 & $0.0081 ; 0.0120$ & Beta $(92.3,9137.7)$ & \\
\hline \multicolumn{5}{|l|}{ Utility } \\
\hline $\begin{array}{l}\text { Relation between EQ-5d } \\
\text { and BASFI and BASDAI }\end{array}$ & & & & Ara et al. [20] \\
\hline Constant & 0.924 & $0.890 ; 0.957$ & Normal $\left(0.924,0.017^{2}\right)$ & \\
\hline BASFI & -0.004 & $-0.0057 ;-0.0029$ & Normal $\left(-0.004,0.0007^{2}\right)$ & \\
\hline BASDAI & -0.004 & $-0.0056 ;-0.0024$ & Normal $\left(-0.004,0.0008^{2}\right)$ & \\
\hline \multicolumn{5}{|l|}{$\begin{array}{l}\text { Disutility due to adverse } \\
\text { events (adjusted for } \\
\text { duration) }\end{array}$} \\
\hline Surgery for PUB & 0.080 & $0.069 ; 0.092$ & \multirow{13}{*}{ Beta distributions } & Moore et al. [29] \\
\hline $\begin{array}{l}\text { Inpatient treatment for } \\
\text { PUB }\end{array}$ & 0.062 & $0.052 ; 0.072$ & & \\
\hline $\begin{array}{l}\text { Outpatient treatment for } \\
\text { PUB }\end{array}$ & 0.051 & $0.042 ; 0.060$ & & \\
\hline $\begin{array}{l}\text { Inpatient investigation for } \\
\text { suspected PUB }\end{array}$ & 0.062 & $0.052 ; 0.072$ & & \\
\hline $\begin{array}{l}\text { Outpatient investigation } \\
\text { for suspected PUB }\end{array}$ & 0.025 & $0.021 ; 0.030$ & & \\
\hline $\begin{array}{l}\text { Minor GI symptoms } \\
\text { requiring treatment }\end{array}$ & 0.015 & $0.012 ; 0.019$ & & \\
\hline $\begin{array}{l}\text { Minor GI symptoms not } \\
\text { requiring treatment }\end{array}$ & 0.00004 & $0.00000 ; 0.00032$ & & \\
\hline Thrombotic CV event & 0.294 & $0.256 ; 0.331$ & & Moore et al. [29] \\
\hline Edema & 0.020 & $0.016 ; 0.024$ & & Revicki [33] \\
\hline Hypertension & 0.001 & $0.000 ; 0.002$ & & Stason and Weinstein, [34] \\
\hline Hepatic & 0.055 & $0.040 ; 0.072$ & & Nichol et al. [35] \\
\hline $\mathrm{CHF}$ & 0.002 & $0.001 ; 0.002$ & & Wong et al, [36] \\
\hline Renal & 0.020 & $0.016 ; 0.024$ & & Revicki [33] \\
\hline \multicolumn{5}{|l|}{ Costs of events (NOK) } \\
\hline Surgery for PUB & 22,904 & 18,$900 ; 27,300$ & & \\
\hline $\begin{array}{l}\text { Inpatient treatment for } \\
\text { PUB }\end{array}$ & 22,904 & 18,$900 ; 27,300$ & & \\
\hline
\end{tabular}


Table 3: Continued.

\begin{tabular}{|c|c|c|c|c|}
\hline Parameter & Value & $\begin{array}{c}\text { Uncertainty } \\
\text { range/95\% credible } \\
\text { interval }\end{array}$ & $\begin{array}{l}\text { Assumed uncertainty } \\
\text { distribution }\end{array}$ & Source \\
\hline $\begin{array}{l}\text { Outpatient treatment for } \\
\text { PUB }\end{array}$ & 2,231 & 2,$038 ; 2,437$ & Gamma distributions & \multirow{4}{*}{$\begin{array}{l}\text { Resource use from Jansen } \\
\text { et al. [19]; drug acquisition } \\
\text { costs from NoMA } \\
\text { (September 2007); GP costs } \\
\text { from Norwegian Medical } \\
\text { Association; DRG prices } \\
\text { from ISF 2007 [37]; }\end{array}$} \\
\hline $\begin{array}{l}\text { Inpatient investigation for } \\
\text { suspected PUB }\end{array}$ & 22,295 & 18,$240 ; 26,700$ & & \\
\hline $\begin{array}{l}\text { Outpatient investigation } \\
\text { for suspected PUB }\end{array}$ & 1,297 & 1,$157 ; 1,445$ & & \\
\hline $\begin{array}{l}\text { Minor GI symptoms } \\
\text { requiring treatment }\end{array}$ & 568 & $507 ; 636$ & & \\
\hline Thrombotic CV event & 95,555 & - & - & $\begin{array}{l}\text { NoMA (September 2007); } \\
\text { ISF } 2007 \text { [37]; }\end{array}$ \\
\hline $\mathrm{CHF}$ & 45,958 & - & - & $\begin{array}{l}\text { NoMA (September 2007); } \\
\text { ISF } 2007 \text { [37]; }\end{array}$ \\
\hline \multicolumn{5}{|l|}{ Annual drug costs (NOK) } \\
\hline Etoricoxib (90 mg) & 4,654 & - & - & \multirow{7}{*}{ NoMA (September 2007) } \\
\hline Celecoxib (200 mg) & 3,318 & - & - & \\
\hline Celecoxib (400 mg) & 6,636 & - & - & \\
\hline Diclofenac (150 mg) & 1,588 & - & - & \\
\hline Naproxen (1000 mg) & 1,380 & - & - & \\
\hline PPI (omeprazole) & 3,050 & - & - & \\
\hline Aspirin (75 mg) & 383 & - & - & \\
\hline Anti-TNF $\alpha$ tx cost & 143,322 & - & - & NoMA (September 2007) \\
\hline
\end{tabular}

than $96 \%$ for WTP of 500,000 NOK and higher. At 5 and 30 years, there is a more than $99 \%$ probability that etoricoxib is the most cost-effective intervention. Figure 3 provides an overview which of the parameters have the greatest impact on (uncertainty) in model outcomes.

3.1.1. Alternative Scenarios. When celecoxib $200 \mathrm{mg}$ was used as a comparator instead of celecoxib $200 \mathrm{mg} \& 400 \mathrm{mg}$ combined, etoricoxib was no longer economically dominant at 1 year. Etoricoxib is 1,322 NOK more expensive. Given the QALY gain of 0.07 , this translates into a cost per QALY of 17,882 NOK, a cost-effective result.

Scenarios where (1) only GI events were included as adverse events, (2) only CV events were included as adverse events, (3) no adverse events were included, (4) no discounting was applied, (5) 8\% discounting was applied, (6) BASFI was assumed to be stable over time, and (7) assuming an average age of 20 years provided comparable cost-effectiveness results as the base-case analysis. Only for the scenario where anti-TNF $\alpha$ costs were set to zero, etoricoxib was no longer dominant. However, etoricoxib can still be considered cost-effective, independent of the time horizon (see Table 6).

\section{Discussion}

The economic evaluation demonstrated that etoricoxib $(90 \mathrm{mg})$ is an economically superior treatment of AS to celecoxib ( $200 \& 400 \mathrm{mg}$ ), diclofenac $(150 \mathrm{mg})$, and naproxen

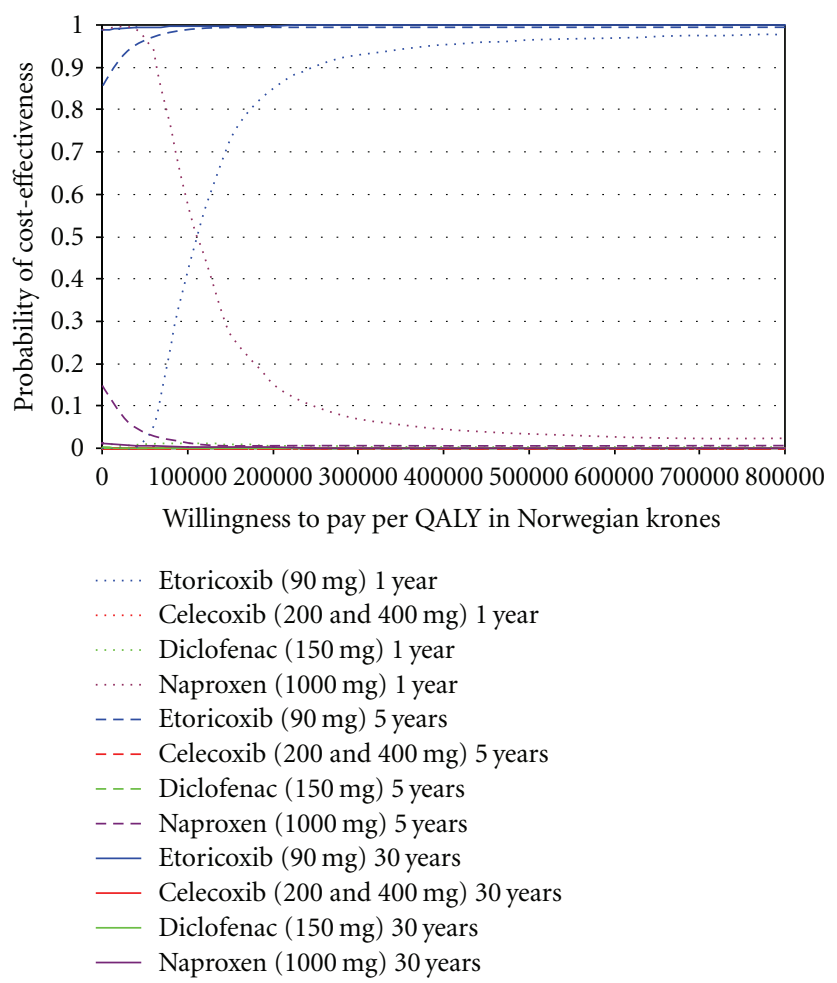

FIgURE 2: Cost-effectiveness acceptability curves reflecting the probability of cost-effectiveness for etoricoxib, celecoxib (200 \& $400 \mathrm{mg}$ ), diclofenac, and naproxen at a followup of 1 year, 5 years, and 30 years (base-case scenario). 
TABLE 4: Estimated effects and costs by treatment (base-case scenario).

\begin{tabular}{|c|c|c|c|c|c|c|c|c|c|c|c|c|}
\hline \multirow{3}{*}{ Life years } & \multicolumn{3}{|c|}{ Etoricoxib (90 mg) } & \multicolumn{3}{|c|}{ Celecoxib (200 \& $400 \mathrm{mg}$ ) } & \multicolumn{3}{|c|}{ Diclofenac (150 mg) } & \multicolumn{3}{|c|}{ Naproxen (1000 mg) } \\
\hline & \multirow{2}{*}{ Estimate } & \multicolumn{2}{|c|}{$95 \% \mathrm{CrI}$} & \multirow[t]{2}{*}{ Estimate } & \multicolumn{2}{|c|}{$95 \% \mathrm{CrI}$} & \multirow[t]{2}{*}{ Estimate } & \multicolumn{2}{|c|}{$95 \% \mathrm{CrI}$} & \multirow[t]{2}{*}{ Estimate } & \multicolumn{2}{|c|}{$95 \% \mathrm{CrI}$} \\
\hline & & & & & & & & & & & & \\
\hline 1 yrs & 1 & 1 & 1 & 1 & 1 & 1 & 1 & 1 & 1 & 1 & 1 & 1 \\
\hline 5 yrs & 4.59 & 4.59 & 4.60 & 4.59 & 4.59 & 4.60 & 4.59 & 4.59 & 4.59 & 4.59 & 4.59 & 4.60 \\
\hline 30 yrs & 16.72 & 16.69 & 16.76 & 16.76 & 16.73 & 16.79 & 16.73 & 16.69 & 16.76 & 16.76 & 16.71 & 16.80 \\
\hline \multicolumn{13}{|l|}{ QALYs } \\
\hline $1 \mathrm{yrs}$ & 0.74 & 0.66 & 0.80 & 0.67 & 0.59 & 0.75 & 0.69 & 0.61 & 0.76 & 0.70 & 0.62 & 0.77 \\
\hline 5 yrs & 3.34 & 3.02 & 3.64 & 3.14 & 2.78 & 3.48 & 3.17 & 2.82 & 3.50 & 3.22 & 2.88 & 3.54 \\
\hline 30 yrs & 11.16 & 9.85 & 12.42 & 10.66 & 9.24 & 12.04 & 10.71 & 9.30 & 12.08 & 10.80 & 9.41 & 12.15 \\
\hline \multirow{3}{*}{$P(\text { best })^{2}$} & $98.90 \%$ & \multicolumn{2}{|c|}{ at 1 year } & $0.00 \%$ & \multicolumn{2}{|c|}{ at 1 year } & $0.13 \%$ & \multicolumn{2}{|c|}{ at 1 year } & $0.98 \%$ & \multicolumn{2}{|c|}{ at 1 year } \\
\hline & $98.94 \%$ & \multicolumn{2}{|c|}{ at 5 years } & $0.00 \%$ & \multicolumn{2}{|c|}{ at 5 years } & $0.11 \%$ & \multicolumn{2}{|c|}{ at 5 years } & $0.95 \%$ & \multicolumn{2}{|c|}{ at 5 years } \\
\hline & $99.96 \%$ & \multicolumn{2}{|c|}{ at 30 years } & $0.00 \%$ & \multicolumn{2}{|c|}{ at 30 years } & $0.00 \%$ & at 30 & years & $0.04 \%$ & at 30 & years \\
\hline $\begin{array}{l}\text { Treatment } \\
\text { cost (NOK }\end{array}$ & & & & & & & & & & & & \\
\hline $1 \mathrm{yrs}$ & 4,654 & 4,654 & 4,654 & 4,977 & 4,977 & 4,977 & 1,588 & 1,588 & 1,588 & 1,380 & 1,380 & 1,380 \\
\hline 5 yrs & 50,020 & 41,400 & 62,060 & 74,940 & 62,790 & 89,160 & 60,250 & 44,380 & 80,180 & 59,030 & 43,100 & 79,000 \\
\hline $30 \mathrm{yrs}$ & 628,200 & 463,300 & 823,600 & 740,500 & 544,400 & 971,100 & 710,400 & 517,500 & 937,800 & 708,900 & 516,200 & 936,000 \\
\hline $\begin{array}{l}\text { GI event ce } \\
(\mathrm{NOK})\end{array}$ & & & & & & & & & & & & \\
\hline $1 \mathrm{yrs}$ & 109 & 69 & 158 & 124 & 65 & 214 & 236 & 144 & 341 & 236 & 144 & 341 \\
\hline 5 yrs & 554 & 360 & 784 & 648 & 391 & 977 & 939 & 576 & 1,356 & 943 & 579 & 1,361 \\
\hline 30 yrs & 1,159 & 743 & 1,644 & 1,069 & 654 & 1,579 & 1,453 & 873 & 2,148 & 1,469 & 881 & 2,173 \\
\hline $\begin{array}{l}\text { Thrombot } \\
\text { CV event } \\
\text { (NOK) }\end{array}$ & & & & & & & & & & & & \\
\hline $1 \mathrm{yrs}$ & 1,148 & 1,027 & 1,278 & 1,148 & 1,027 & 1,278 & 1,208 & 1,082 & 1,345 & 714 & 360 & 1,271 \\
\hline 5 yrs & 5,065 & 4,617 & 5,542 & 4,871 & 4,476 & 5,289 & 5,081 & 4,535 & 5,672 & 3,654 & 2,590 & 5,309 \\
\hline $30 \mathrm{yrs}$ & 10,060 & 8,452 & 11,650 & 7,696 & 6,712 & 8,756 & 8,293 & 6,852 & 9,920 & 6,541 & 4,888 & 8,833 \\
\hline $\begin{array}{l}\text { Other AE } \\
\text { costs (NOI }\end{array}$ & & & & & & & & & & & & \\
\hline $1 \mathrm{yrs}$ & 202 & 146 & 268 & 202 & 146 & 268 & 120 & 77 & 171 & 120 & 77 & 171 \\
\hline $5 \mathrm{yrs}$ & 814 & 612 & 1,048 & 723 & 555 & 918 & 502 & 323 & 718 & 504 & 324 & 720 \\
\hline $30 \mathrm{yrs}$ & 1,507 & 1,098 & 1,991 & 1,048 & 795 & 1,342 & 820 & 513 & 1,201 & 828 & 517 & 1,214 \\
\hline $\begin{array}{l}\text { Total costs } \\
(\mathrm{NOK})\end{array}$ & & & & & & & & & & & & \\
\hline $1 \mathrm{yrs}$ & 6,115 & 5,974 & 6,267 & 6,452 & 6,300 & 6,618 & 3,152 & 2,981 & 3,332 & 2,449 & 2,073 & 3,015 \\
\hline 5 yrs & 56,450 & 47,920 & 68,450 & 81,190 & 69,120 & 95,230 & 66,780 & 51,010 & 86,440 & 64,130 & 48,120 & 84,220 \\
\hline 30 yrs & 640,900 & 476,900 & 835,600 & 750,300 & 554,500 & 980,800 & 721,000 & 528,800 & 947,700 & 717,800 & 526,000 & 944,700 \\
\hline & $0.00 \%$ & at 1 & year & $0.00 \%$ & at 1 & year & $1.15 \%$ & at 1 & year & $98.85 \%$ & at 1 & year \\
\hline$P$ (best $^{2}$ & $85.26 \%$ & at 5 & rears & $0.00 \%$ & at 5 & rears & $0.18 \%$ & at 5 & rears & $14.57 \%$ & at 5 & rears \\
\hline & $98.92 \%$ & at 30 & years & $0.01 \%$ & at 30 & years & $0.03 \%$ & at 30 & years & $1.04 \%$ & at 30 & years \\
\hline
\end{tabular}

${ }^{1}$ All results are discounted, $4.0 \%$ for effects and costs.

${ }^{2}$ Probability that a certain intervention provides best outcomes (i.e., greatest QALYs, lowest costs).

(1000 mg) for both QALY gains and cost savings for a time horizon longer than 5 years. For a 1-year time horizon, etoricoxib is associated with greater costs than diclofenac (150 mg) and naproxen (1000 mg), but can still be considered cost effective.

In addition to drug acquisition costs for the NSAIDs, also costs for anti-TNF $\alpha$ treatment after failure on NSAIDs were taken into consideration. Given the model structure we opted for, the average duration on any NSAID was estimated to be 11.2 years (95\% CrI 9.0-13.2) for the patients starting with etoricoxib, 7.8 (6.8-9.0) years with celecoxib, $8.3(6.8-10.1)$ years with diclofenac, and 8.4 (6.9-10.2) years with naproxen. These differences explain the savings regarding drug acquisition observed when initiating treatment with etoricoxib over the other treatment strategies observed at the 5,- and 30-year time horizon. However, when 
TABLE 5: Cost-effectiveness of etoricoxib relative to other interventions (base-case scenario).

\begin{tabular}{|c|c|c|c|c|c|c|c|c|c|}
\hline \multirow{2}{*}{1 year } & \multicolumn{3}{|c|}{ Incremental costs in $\mathrm{NOK}$} & \multicolumn{3}{|c|}{ Incremental QALYs } & \multicolumn{3}{|c|}{ Incremental cost-effectiveness ratio } \\
\hline & Estimate & \multicolumn{2}{|c|}{ 95\% CrI } & Estimate & \multicolumn{2}{|c|}{ 95\% CrI } & Estimate & \multicolumn{2}{|c|}{$95 \% \mathrm{CrI}$} \\
\hline $\begin{array}{l}\text { Etoricoxib }(90 \mathrm{mg}) \\
\text { versus celecoxib ( } 200 \\
\text { \& } 400 \mathrm{mg})\end{array}$ & -337 & -411 & -280 & 0.06 & 0.03 & 0.10 & Dominant & Dominant & Dominant \\
\hline $\begin{array}{l}\text { Etoricoxib ( } 90 \mathrm{mg} \text { ) } \\
\text { versus diclofenac }\end{array}$ & 2,964 & 2,753 & 3,173 & 0.05 & 0.02 & 0.09 & 59,221 & 33,180 & 184,500 \\
\hline $\begin{array}{l}\text { Etoricoxib }(90 \mathrm{mg}) \\
\text { versus naproxen }\end{array}$ & 3,666 & 3,109 & 4,046 & 0.03 & 0.01 & 0.07 & 107,256 & 51,320 & 494,300 \\
\hline \multicolumn{10}{|l|}{5 years } \\
\hline $\begin{array}{l}\text { Etoricoxib }(90 \mathrm{mg}) \\
\text { versus celecoxib (200 } \\
\& 400 \mathrm{mg})\end{array}$ & $-24,730$ & $-37,730$ & $-11,720$ & 0.20 & 0.08 & 0.33 & Dominant & Dominant & Dominant \\
\hline $\begin{array}{l}\text { Etoricoxib ( } 90 \mathrm{mg} \text { ) } \\
\text { versus diclofenac }\end{array}$ & $-10,320$ & $-26,070$ & 2,840 & 0.17 & 0.05 & 0.30 & Dominant & Dominant & Dominant \\
\hline $\begin{array}{l}\text { Etoricoxib }(90 \mathrm{mg}) \\
\text { versus naproxen }\end{array}$ & $-7,682$ & $-23,540$ & 5,729 & 0.12 & 0.02 & 0.23 & Dominant & Dominant & Dominant \\
\hline \multicolumn{10}{|l|}{30 years } \\
\hline $\begin{array}{l}\text { Etoricoxib }(90 \mathrm{mg}) \\
\text { versus celecoxib ( } 200 \\
\& 400 \mathrm{mg})\end{array}$ & $-109,400$ & $-198,700$ & $-38,640$ & 0.51 & 0.25 & 0.84 & Dominant & Dominant & Dominant \\
\hline $\begin{array}{l}\text { Etoricoxib (90 mg) } \\
\text { versus diclofenac }\end{array}$ & $-80,060$ & $-164,800$ & $-13,280$ & 0.45 & 0.20 & 0.76 & Dominant & Dominant & Dominant \\
\hline $\begin{array}{l}\text { Etoricoxib ( } 90 \mathrm{mg} \text { ) } \\
\text { versus naproxen }\end{array}$ & $-76,850$ & $-162,100$ & $-9,622$ & 0.36 & 0.13 & 0.66 & Dominant & Dominant & Dominant \\
\hline
\end{tabular}

TABLE 6: Cost-effectiveness of etoricoxib relative to other interventions when anti-TNF $\alpha$ costs are set to zero.

\begin{tabular}{|c|c|c|c|c|c|c|c|c|c|}
\hline \multirow{2}{*}{1 year } & \multicolumn{3}{|c|}{ Incremental costs in $\mathrm{NOK}$} & \multicolumn{3}{|c|}{ Incremental QALYs } & \multicolumn{3}{|c|}{ ICER } \\
\hline & Estimate & \multicolumn{2}{|c|}{$95 \% \mathrm{CrI}$} & Estimate & \multicolumn{2}{|c|}{ 95\% CrI } & Estimate & \multicolumn{2}{|c|}{$95 \% \mathrm{CrI}$} \\
\hline $\begin{array}{l}\text { Etoricoxib }(90 \mathrm{mg}) \\
\text { versus celecoxib }(200 \\
\& 400 \mathrm{mg})\end{array}$ & -337 & -410 & -280 & 0.06 & 0.03 & 0.10 & Dominant & Dominant & Dominant \\
\hline $\begin{array}{l}\text { Etoricoxib (90 mg) } \\
\text { versus diclofenac }\end{array}$ & 2,965 & 2,756 & 3,173 & 0.05 & 0.02 & 0.09 & 59,288 & 33,190 & 188,200 \\
\hline $\begin{array}{l}\text { Etoricoxib (90 mg) } \\
\text { versus naproxen }\end{array}$ & 3,663 & 3,099 & 4,043 & 0.03 & 0.01 & 0.07 & 107,074 & 50,970 & 488,500 \\
\hline \multicolumn{10}{|l|}{5 years } \\
\hline $\begin{array}{l}\text { Etoricoxib }(90 \mathrm{mg}) \\
\text { versus celecoxib ( } 200 \\
\text { \& } 400 \mathrm{mg})\end{array}$ & 2,194 & 426 & 3,745 & 0.20 & 0.08 & 0.33 & 10,926 & 2083 & 30820 \\
\hline $\begin{array}{l}\text { Etoricoxib }(90 \mathrm{mg}) \\
\text { versus diclofenac }\end{array}$ & 10,560 & 9,058 & 11,880 & 0.17 & 0.05 & 0.30 & 62,411 & 34650 & 198400 \\
\hline $\begin{array}{l}\text { Etoricoxib (90 mg) } \\
\text { versus naproxen }\end{array}$ & 12,370 & 10,330 & 14,000 & 0.12 & 0.02 & 0.23 & 103,083 & 49220 & 465100 \\
\hline \multicolumn{10}{|l|}{30 years } \\
\hline $\begin{array}{l}\text { Etoricoxib }(90 \mathrm{mg}) \\
\text { versus celecoxib }(200 \\
\& 400 \mathrm{mg})\end{array}$ & 15,740 & 5,398 & 25,490 & 0.51 & 0.25 & 0.84 & 31,009 & 14330 & 59810 \\
\hline $\begin{array}{l}\text { Etoricoxib }(90 \mathrm{mg}) \\
\text { versus diclofenac }\end{array}$ & 23,910 & 14,520 & 32,990 & 0.45 & 0.20 & 0.76 & 53,181 & 34020 & 103800 \\
\hline $\begin{array}{l}\text { Etoricoxib }(90 \mathrm{mg}) \\
\text { versus naproxen }\end{array}$ & 25,660 & 16,150 & 34,810 & 0.36 & 0.13 & 0.66 & 70,825 & 42830 & 170900 \\
\hline
\end{tabular}


the anti-TNF $\alpha$ acquisition costs are taken out of the picture, etoricoxib is still economically more favorable than celecoxib, diclofenac, or naproxen (see Table 6).

For the current economic evaluation, a comprehensive decision modeling approach was used. With this approach, an indirect comparison of efficacy and safety estimates were integrated with cost-effectiveness analysis in a single framework [18]. The advantage of this approach is that no assumptions were made regarding the uncertainty distributions used for sensitivity analysis; the Bayesian posterior uncertainty distributions of the treatment effect and GI and CV events as obtained from the MTC were directly propagated through the Markov model. The most important factor in the cost-effectiveness analysis was the probability of discontinuation as estimated with the MTC (see Figure 3)

The etoricoxib GI safety data as used in the analysis were obtained from clinical trials in OA, RA, AS, and chronic low back pain patients [11]; the celecoxib GI safety data were obtained from the CLASS study [14]. These data were assumed applicable for AS. It could be argued that AS patients are likely younger than the average patient in the GI meta-analysis and, therefore, have a lower GI risk. However, AS patients often receive higher nsNSAID doses than patients with other arthritic conditions, thereby increasing their risk for GI events. Risk estimates of CV events were based on the MEDAL programme comparing etoricoxib with diclofenac among OA and RA patients and a meta-analysis of 12 phase II-IV clinical trials comparing etoricoxib with naproxen, among OA, RA, AS, and chronic low back pain patients $[15,30]$. As AS patients are on average younger than patients in the MEDAL programme and the meta-analysis, it can be argued that the risk for $\mathrm{CV}$ events might have been overestimated in the model.

In the model, the risk for a second CV event was set to be the same as before the $\mathrm{CV}$ event, assuming that the increased $\mathrm{CV}$ risk due to the history of a CV event was counterbalanced by adding aspirin to the NSAID. However, the history of a $\mathrm{CV}$ event might have a bigger impact than the protective effect by aspirin, which would imply an underestimation of the risk of $\mathrm{CV}$ events in the model, and, therefore, an underestimation of the costs due to $\mathrm{CV}$ events. The effect on the difference in costs, however, would be limited because the underestimation applies to both treatment initiated with etoricoxib and nsNSAIDs.

Costs associated with severity of AS (i.e., GP visits, specialist visits, paramedical visits, hospitalization, technical examinations, adaptations and aids) were not included in the analysis. For the UK, Botteman et al. showed that each incremental change in one unit of BASDAI (0-100 scale) was estimated to be associated with a direct medical cost increase according to Cost $=£ 708.45+\mathfrak{E} 75.00 *$ BASDAI [51]. For the Norwegian situation, no such information was available. As a result, the cost savings of treatment of AS have probably been underestimated, especially for etoricoxib.

This evaluation was performed for the Norwegian local situation. In general, it is difficult to "transfer" costeffectiveness estimates obtained for one country to another, due to differences in treatment practices, resource use, and unit cost data, among other. Although the cost-effectiveness

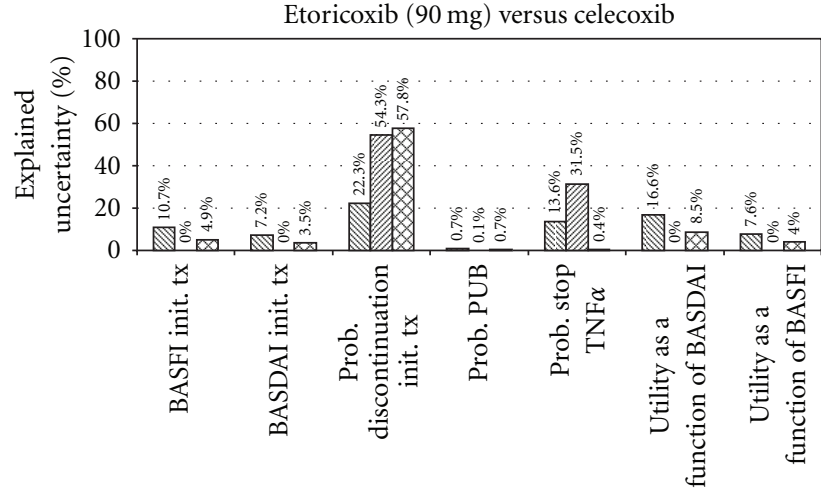

(a)

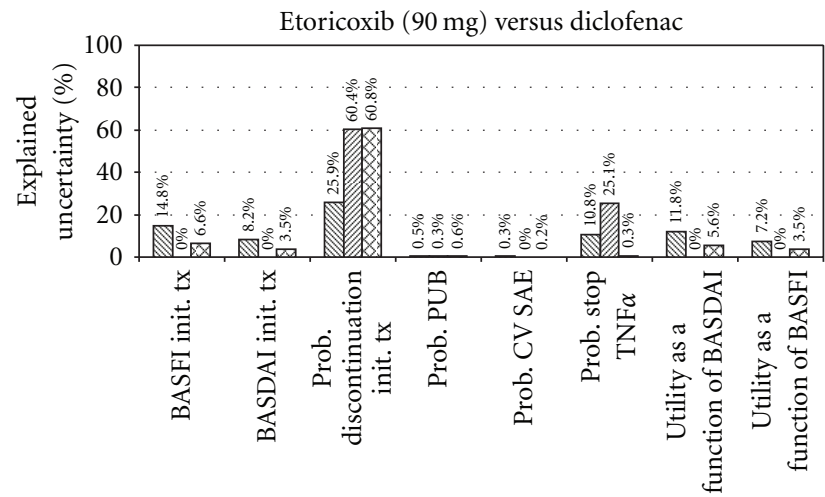

(b)

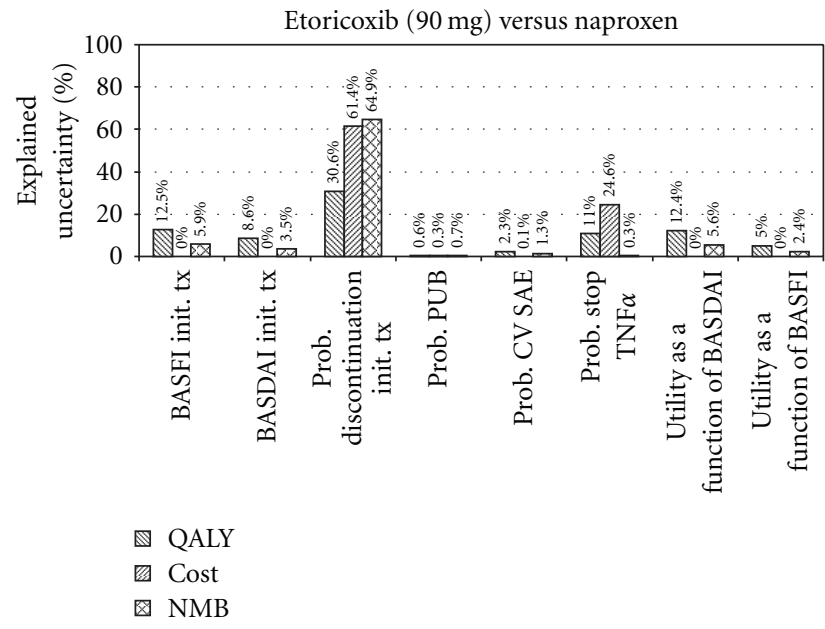

(c)

Figure 3: Proportion of explained uncertainty in model outcomes (incremental QALYs, costs, and net-monetary benefit at WTP of $400,000 \mathrm{NOK}$ ) by the most relevant variables for the comparison of etoricoxib (90 mg) versus celecoxib, diclofenac, and naproxen (basecase scenario).

findings in this study were primarily driven by differences in efficacy of the compared interventions, the cost-effectiveness of the different NSAIDs for the management of ankylosing spondylitis in other countries needs to be confirmed with country-specific analysis. 
In conclusion, given the underlying assumptions and current evidence available, this economic evaluation demonstrated that etoricoxib is a cost-saving and QALY gaining therapy for AS in Norway from a health care perspective.

\section{Funding}

This study was funded by Merck \& Co., Inc.

\section{Disclosure Statement}

J. P. Jansen is an employee of Mapi Values. Mapi Values received consultancy fees from Merck \& Co. Inc. related to this paper. S. Taylor is an employee of Merck \& Co. Inc.

\section{References}

[1] L. Gossec, D. van der Heijde, A. Melian et al., "Efficacy of cyclo-oxygenase-2 inhibition by etoricoxib and naproxen on the axial manifestations of ankylosing spondylitis in the presence of peripheral arthritis," Annals of the Rheumatic Diseases, vol. 64, no. 11, pp. 1563-1567, 2005.

[2] A. Saraux, F. Guillemin, P. Guggenbuhl et al., "Prevalence of spondyloarthropathies in France: 2001," Annals of the Rheumatic Diseases, vol. 64, no. 10, pp. 1431-1435, 2005.

[3] J. Braun, M. Bollow, G. Remlinger et al., "Prevalence of spondylarthropathies in HLA-B27 positive and negative blood donors," Arthritis and Rheumatism, vol. 41, no. 1, pp. 58-67, 1998.

[4] N. Akkoc, M. A. Khan, J. Braun, J. Listing, and J. Sieper, "Overestimation of the prevalence of ankylosing spondylitis in the Berlin study: comment on the article by Braun et al," Arthritis and Rheumatism, vol. 52, no. 12, pp. 4048-4050, 2005.

[5] A. Boonen, D. van der Heijde, R. Landewé et al., "Direct costs of ankylosing spondylitis and its determinants: an analysis among three European countries," Annals of the Rheumatic Diseases, vol. 62, no. 8, pp. 732-740, 2003.

[6] G. Kobelt, P. Andlin-Sobocki, S. Brophy, L. Jönsson, A. Calin, and J. Braun, "The burden of ankylosing spondylitis and the cost-effectiveness of treatment with infliximab (Remicade (B)," Rheumatology, vol. 43, no. 9, pp. 1158-1166, 2004.

[7] J. Sieper and J. Braun, "New treatment options in ankylosing spondylitis: a role for anti-TNF $\alpha$ therapy," Annals of the Rheumatic Diseases, vol. 60, no. 3, pp. iii58-iii61, 2001.

[8] J. Braun, T. Pham, J. Sieper et al., "International ASAS consensus statement for the use of anti-tumour necrosis factor agents in patients with ankylosing spondylitis," Annals of the Rheumatic Diseases, vol. 62, no. 9, pp. 817-824, 2003.

[9] J. Zochling, D. van der Heijde, M. Dougados, and J. Braun, "Current evidence for the management of ankylosing spondylitis: a systematic literature review for the ASAS/EULAR management recommendations in ankylosing spondylitis," Annals of the Rheumatic Diseases, vol. 65, no. 4, pp. 423-432, 2006.

[10] A. Keat, N. Barkham, A. Bhalla et al., "BSR guidelines for prescribing TNF- $\alpha$ blockers in adults with ankylosing spondylitis. Report of a working party of the British Society for Rheumatology," Rheumatology, vol. 44, no. 7, pp. 939-947, 2005.
[11] D. R. Ramey, D. J. Watson, C. Yu, J. A. Bolognese, S. P. Curtis, and A. S. Reicin, "The incidence of upper gastrointestinal adverse events in clinical trials of etoricoxib vs. non-selective NSAIDs: an updated combined analysis," Current Medical Research and Opinion, vol. 21, no. 5, pp. 715-722, 2005.

[12] R. H. Hunt, S. Harper, P. Callegari et al., "Complementary studies of the gastrointestinal safety of the cyclo-oxygenase-2selective inhibitor etoricoxib," Alimentary Pharmacology and Therapeutics, vol. 17, no. 2, pp. 201-210, 2003.

[13] R. H. Hunt, S. Harper, D. J. Watson et al., "The gastrointestinal safety of the COX-2 selective inhibitor etoricoxib assessed by both endoscopy and analysis of upper gastrointestinal events," American Journal of Gastroenterology, vol. 98, no. 8, pp. 17251733, 2003.

[14] F. E. Silverstein, G. Faich, J. L. Goldstein et al., "Gastrointestinal toxicity with Celecoxib vs nonsteroidal anti-inflammatory drugs for osteoarthritis and reumatoid arthritis: the CLASS study: a randomized controlled trial," Journal of the American Medical Association, vol. 284, no. 10, pp. 1247-1255, 2000.

[15] C. P. Cannon, S. P. Curtis, G. A. FitzGerald et al., "Cardiovascular outcomes with etoricoxib and diclofenac in patients with osteoarthritis and rheumatoid arthritis in the Multinational Etoricoxib and Diclofenac Arthritis Long-term (MEDAL) programme: a randomised comparison," The Lancet, vol. 368, no. 9549, pp. 1771-1781, 2006.

[16] D. van der Heijde, H. S. B. Baraf, C. Ramos-Remus et al., "Evaluation of the efficacy of etoricoxib in ankylosing spondylitis: results of a fifty-two-week, randomized, controlled study," Arthritis and Rheumatism, vol. 52, no. 4, pp. 1205-1215, 2005.

[17] J. Sieper, T. Klopsch, M. Richter et al., "Comparison of two different dosages of celecoxib with diclofenac for the treatment of active ankylosing spondylitis: results of a 12week randomised, double-blind, controlled study," Annals of the Rheumatic Diseases, vol. 67, no. 3, pp. 323-329, 2008.

[18] N. J. Cooper, A. J. Sutton, and K. R. Abrams, "Decision analytical economic modelling within a Bayesian framework: application to prophylactic antibiotics use for caesarean section," Statistical Methods in Medical Research, vol. 11, no. 6, pp. 491-512, 2002.

[19] J. P. Jansen, S. Gaugris, E. H. Choy, A. Ostor, J. T. Nash, and W. Stam, "Cost-effectiveness evaluation of etoricoxib versus celecoxib and non-selective NSAIDs in the treatment of ankylosing spondylitis," PharmacoEconomics, vol. 28, no. 4, pp. 323-344, 2010.

[20] R. M. Ara, A. V. Reynolds, and P. Conway, "The costeffectiveness of etanercept in patients with severe ankylosing spondylitis in the UK," Rheumatology, vol. 46, no. 8, pp. 13381344, 2007.

[21] G. Lu and A. E. Ades, "Combination of direct and indirect evidence in mixed treatment comparisons," Statistics in Medicine, vol. 23, no. 20, pp. 3105-3124, 2004.

[22] J. P. Jansen, B. Crawford, G. Bergman, and W. Stam, "Bayesian meta-analysis of multiple treatment comparisons: an introduction to mixed treatment comparisons," Value in Health, vol. 11, no. 5, pp. 956-964, 2008.

[23] A. Boonen, D. van der Heijde, J. L. Severens et al., "Markov model into the cost-utility over five years of etanercept and infliximab compared with usual care in patients with active ankylosing spondylitis," Annals of the Rheumatic Diseases, vol. 65, no. 2, pp. 201-208, 2006.

[24] A. L. Taylor, C. Balakrishnan, and A. Calin, "Reference centile charts for measures of disease activity, functional impairment, 
and metrology in ankylosing spondylitis," Arthritis and Rheumatism, vol. 41, no. 6, pp. 1119-1125, 1998.

[25] L. E. Kristensen, T. Saxne, and P. Geborek, "The LUNDEX, a new index of drug efficacy in clinical practice: results of a five-year observational study of treatment with infliximab and etanercept among rheumatoid arthritis patients in Southern Sweden," Arthritis and Rheumatism, vol. 54, no. 2, pp. 600 606, 2006.

[26] A. Barkhuizen, S. Steinfeld, J. Robbins, C. West, J. Coombs, and S. Zwillich, "Celecoxib is efficacious and well tolerated in treating signs and symptoms of ankylosing spondylitis," Journal of Rheumatology, vol. 33, no. 9, pp. 1805-1812, 2006.

[27] M. Dougados, J. M. Béhier, I. Jolchine et al., "Efficacy of celecoxib, a cyclooxygenase 2-specific inhibitor, in the treatment of ankylosing spondylitis: a six-week controlled study with comparison against placebo and against a conventional nonsteroidal antiinflammatory drug," Arthritis and Rheumatism, vol. 44, no. 1, pp. 180-185, 2001.

[28] L. Laine, S. P. Curtis, B. Cryer, A. Kaur, and C. P. Cannon, "Assessment of upper gastrointestinal safety of etoricoxib and diclofenac in patients with osteoarthritis and rheumatoid arthritis in the Multinational Etoricoxib and Diclofenac Arthritis Long-term (MEDAL) programme: a randomised comparison," The Lancet, vol. 369, no. 9560, pp. 465-473, 2007.

[29] A. Moore, C. Phillips, E. Hunsche, J. Pellissier, and S. Crespi, "Economic evaluation of etoricoxib versus non-selective NSAIDs in the treatment of osteoarthritis and rheumatoid arthritis patients in the UK," PharmacoEconomics, vol. 22, no. 10, pp. 643-660, 2004.

[30] S. P. Curtis, S. Mukhopadhyay, and D. Ramey, "Cardiovascular safety summary associated with the etoricoxib development program," Arthritis \& Rheumatism, vol. 48, pp. S35-S750, 2003.

[31] M. R. Tramèr, R. A. Moore, D. J. M. Reynolds, and H. J. McQuay, "Quantitative estimation of rare adverse events which follow a biological progression: a new model applied to chronic NSAID use," Pain, vol. 85, no. 1-2, pp. 169-182, 2000.

[32] Life Tables for WHO Member States, 2008, http://www .who.int/healthinfo/statistics/mortality_life_tables/en/.

[33] D. A. Revicki, "Relationship between health utility and psychometric health status measures," Medical Care, vol. 30, no. 5, pp. MS274-MS282, 1992.

[34] W. B. Stason and M. C. Weinstein, "Allocation of resources to manage hypertension," The New England Journal of Medicine, vol. 296, no. 13, pp. 732-739, 1977.

[35] G. Nichol, P. Kaul, E. Huszti, and J. F. P. Bridges, "Costeffectiveness of cardiac resynchronization therapy in patients with symptomatic heart failure," Annals of Internal Medicine, vol. 141, no. 5, pp. 343-351, 2004.

[36] J. B. Wong, R. S. Koff, F. Tine, and S. G. Pauker, "Costeffectiveness of interferon- $\alpha 2 b$ treatment for hepatitis $B$ e antigen- positive chronic hepatitis B," Annals of Internal Medicine, vol. 122, no. 9, pp. 664-675, 1995.

[37] ISF 2007, "Ministry of Health and Care Services," http://www .helsedirektoratet.no/vp/multimedia/archive/00014/IS-1439_ 14578a.pdf.

[38] F. A. Sonnenberg and J. R. Beck, "Markov models in medical decision making: a practical guide," Medical Decision Making, vol. 13, no. 4, pp. 322-338, 1993.

[39] B. S. Bloom, "Direct medical costs of disease and gastrointestinal side effects during treatment for arthritis," The American Journal of Medicine, vol. 84, no. 2, pp. 20-24, 1988.
[40] A. Maetzel, M. B. Ferraz, and C. Bombardier, "The costeffectiveness of misoprostol in preventing serious gastrointestinal events associated with the use of nonsteroidal antiinflammatory drugs," Arthritis and Rheumatism, vol. 41, no. 1, pp. 16-25, 1998.

[41] R. Knill-Jones, M. Drummond, H. Kohli, and L. Davies, "Economic evaluation of gastric ulcer prophylaxis in patients with arthritis receiving non-steroidal anti-inflammatory drugs," Postgraduate Medical Journal, vol. 66, no. 778, pp. 639-646, 1990.

[42] G. Singh and D. R. Ramey, "NSAID induced gastrointestinal complications: the ARAMIS perspective-1997," Journal of Rheumatology, vol. 25, supplement 51, pp. 8-16, 1998.

[43] G. de Pouvourville, "The economic consequences of NSAIDinduced gastropathy: the French context," Scandinavian Journal of Rheumatology, Supplement, vol. 21, no. 96, pp. 49-53, 1992.

[44] B. Jönsson and U. Haglund, "Cost-effectiveness of misoprostol in Sweden," International Journal of Technology Assessment in Health Care, vol. 8, no. 2, pp. 234-244, 1992.

[45] S. E. Gabriel and E. L. Matteson, "Economic and quality-oflife impact of NSAIDs in rheumatoid arthritis. A conceptual framework and selected literature review," PharmacoEconomics, vol. 8, no. 6, pp. 479-490, 1995.

[46] W. E. Smalley, M. R. Griffin, R. L. Fought, and W. A. Ray, "Excess costs from gastrointestinal disease associated with nonsteroidal anti-inflammatory drugs," Journal of General Internal Medicine, vol. 11, no. 8, pp. 461-469, 1996.

[47] J. T. Edelson, A. N. A. Tosteson, and P. Sax, "Cost-effectiveness of misoprostol for prophylaxis against nonsteroidal antiinflammatory drug-induced gastrointestinal tract bleeding," Journal of the American Medical Association, vol. 264, no. 1, pp. 41-47, 1990.

[48] S. E. Gabriel, M. E. Campion, and W. M. O’Fallon, "Patient preferences for nonsteroidal antiinflammatory drug related gastrointestinal complications and their prophylaxis," Journal of Rheumatology, vol. 20, no. 2, pp. 358-361, 1993.

[49] R. E. Johnson, M. C. Hornbrook, R. S. Hooker, G. T. Woodson, and R. Shneidman, "Analysis of the costs of NSAIDassociated gastropathy. Experience in a US health maintenance organisation," PharmacoEconomics, vol. 12, no. 1, pp. 76-88, 1997.

[50] S. X. Kong, H. T. Hatoum, S. Z. Zhao, N. M. Agrawal, and S. G. Geis, "Prevalence and cost of hospitalization for gastrointestinal complications related to peptic ulcers with bleeding or perforation: comparison of two national databases," American Journal of Managed Care, vol. 4, no. 3, pp. 399-409, 1998.

[51] M. F. Botteman, J. W. Hay, M. P. Luo, A. S. Curry, R. L. Wong, and B. A. van Hout, "Cost effectiveness of adalimumab for the treatment of ankylosing spondylitis in the United Kingdom," Rheumatology, vol. 46, no. 8, pp. 1320-1328, 2007. 


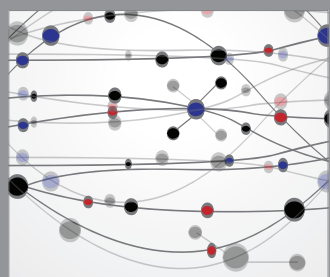

The Scientific World Journal
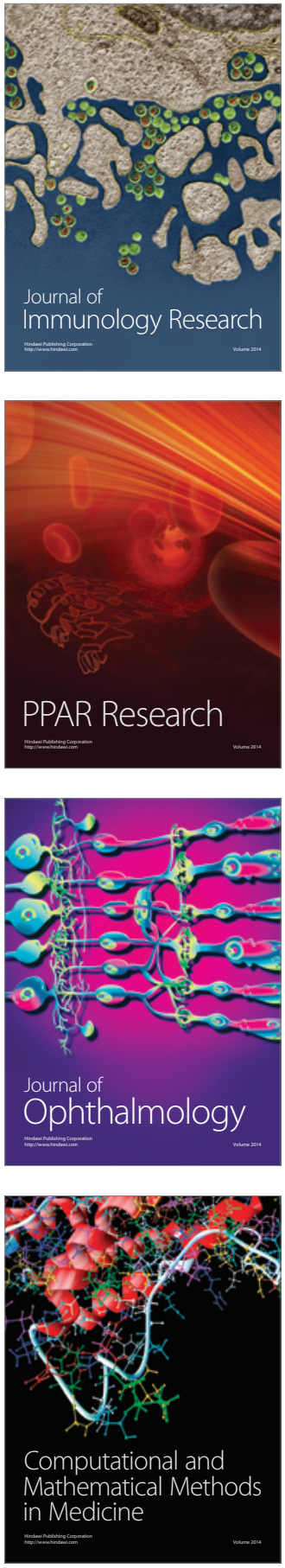

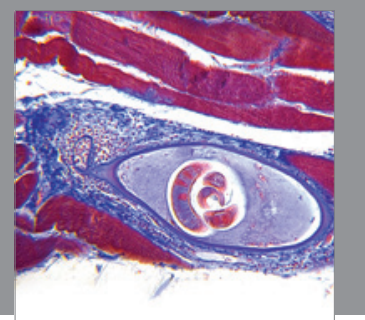

Gastroenterology

Research and Practice
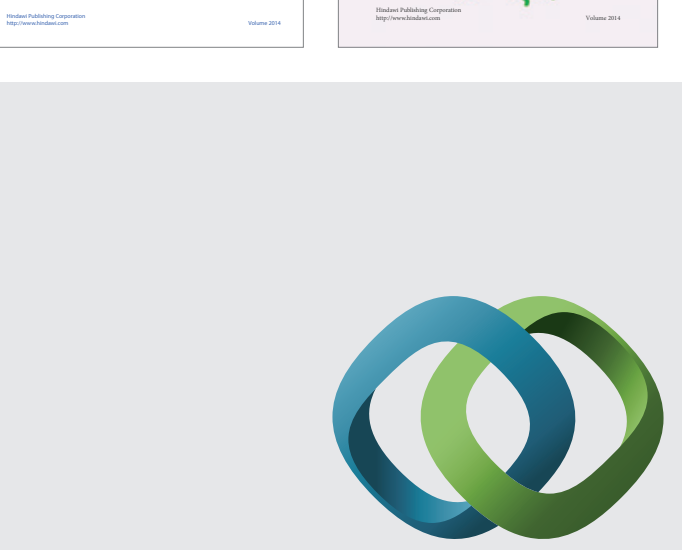

\section{Hindawi}

Submit your manuscripts at

http://www.hindawi.com
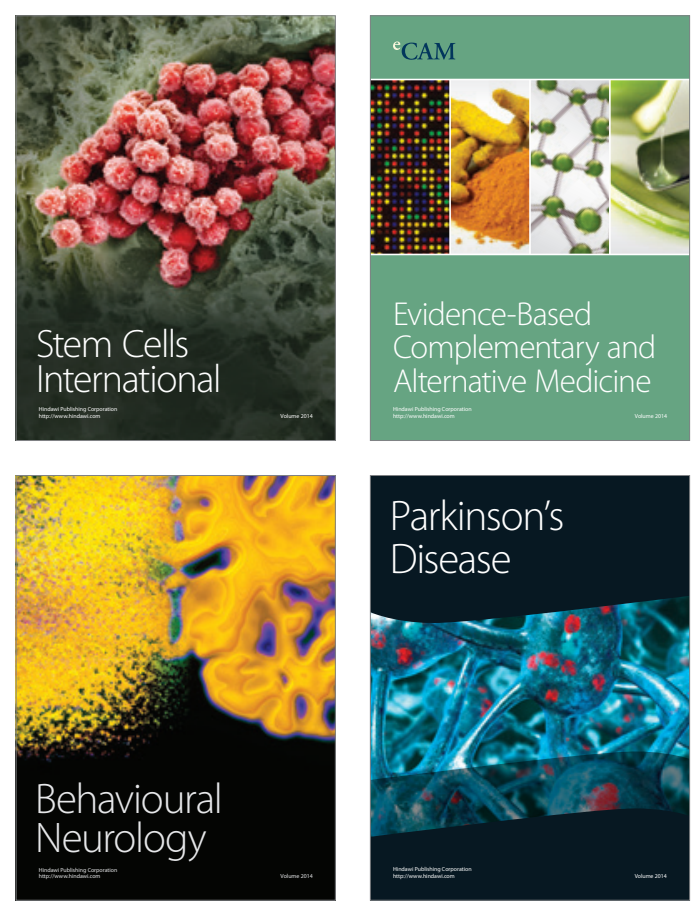

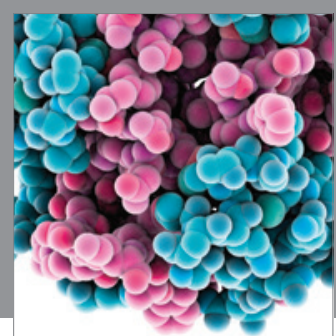

Journal of
Diabetes Research

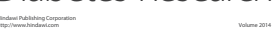

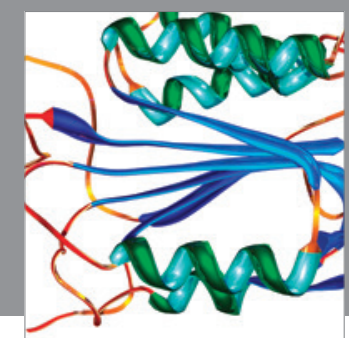

Disease Markers
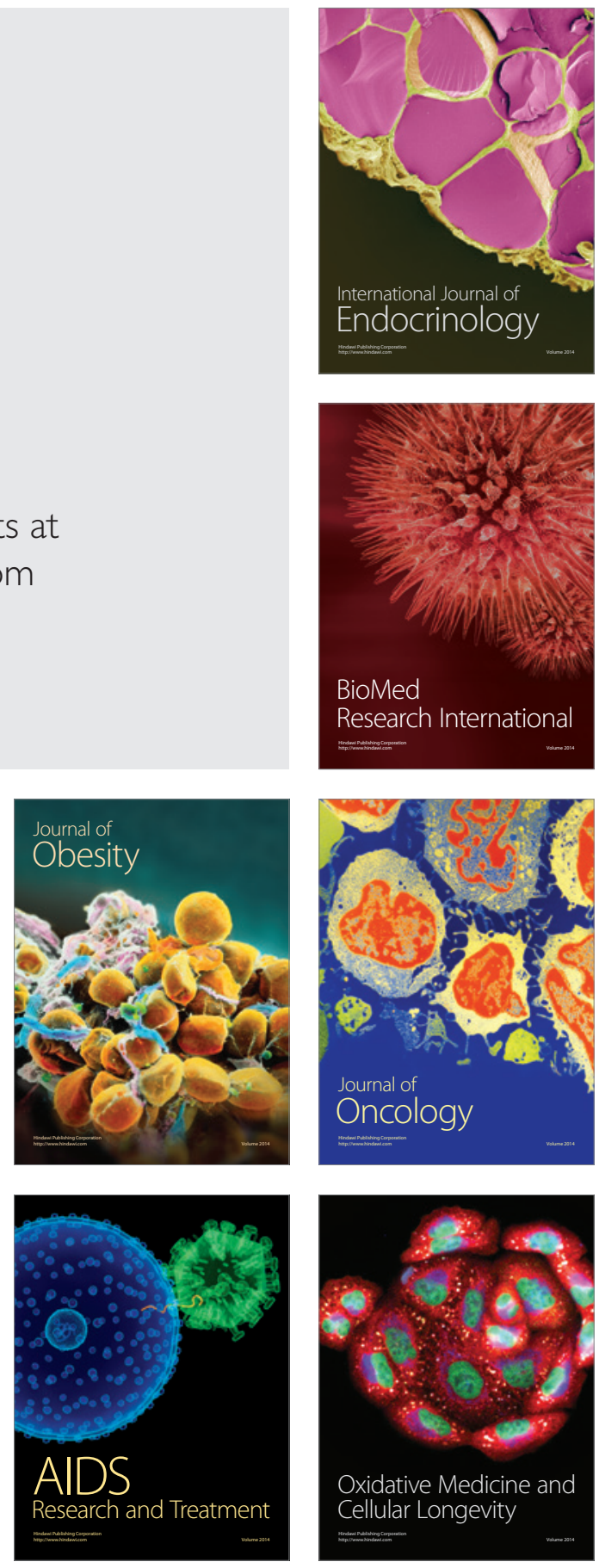